\title{
SHORT REPORT \\ Group $C$ rotavirus infection in patients with acute gastroenteritis in outbreaks in western India between 2006 and 2014
}

\author{
M. S. JOSHI, V. M. JARE AND V. GOPALKRISHNA* \\ Enteric Viruses Group, National Institute of Virology, Pune, India
}

Received 27 April 2016; Final revision 19 September 2016; Accepted 20 September 2016; first published online 26 October 2016

\section{SUMMARY}

Faecal specimens collected from outbreak $(n=253)$ and sporadic $(n=147)$ cases of acute gastroenteritis that occurred in western India between 2006 and 2014 were tested for group C rotavirus (GCR) using partial VP6 gene-based RT-PCR. All specimens were tested previously for the presence of other viral and bacterial aetiological agents by conventional methods. The rate of GCR detection was $8 \cdot 6 \%$ and $0.7 \%$ in outbreak and sporadic cases, respectively. GCR infections prevailed in outbreaks reported from rural areas $(10.9 \%)$ compared to urban areas $(1 \cdot 6 \%)$. Clinical severity score of the patients with GCR infection $(n=23)$ indicated severe disease in the majority $(70 \%)$ of cases. The age distribution analysis indicated $52.1 \%$ of GCR infections in children aged $<10$ years. The male:female ratio in GCR-positive patients was $2 \cdot 3: 1$. Of the 23 GCR-positive cases, 17 (73.9\%) had a sole GCR infection and six had mixed infections with other viral and/or bacterial agents. Phylogenetic analysis of nucleotide sequences classified GCR strains of the study in to $I_{2}$ genotype of the VP6 gene. This is the first study to show the occurrence of GCR in gastroenteritis outbreaks in India.

Key words: Diarrhoea, India, outbreak, sporadic, phylogenetic analysis, rotavirus group C, RT-PCR, VP6 gene.

Acute gastroenteritis (AGE) is a major cause of morbidity and mortality worldwide. It is estimated that $1 \cdot 5-2 \cdot 5$ million deaths and between 3 and 5 billion cases occur annually due to gastroenteritis in children aged $<5$ years. In older children, adolescents and adults, a low mortality and high morbidity with $\sim 2 \cdot 8$ billion episodes per year have been reported [1]. The majority of gastroenteritis episodes in children are due to different viral agents mainly rotavirus, norovirus, astrovirus and adenovirus, among which rotavirus infections are most predominant.

\footnotetext{
* Author for correspondence: Dr V. Gopalkrishna, Enteric Viruses Group, National Institute of Virology, 20-A, Dr Ambedkar Road, PO Box No. 11, Pune 411 001, India.

(Email: gopalvk58@hotmail.com)
}

Rotavirus, a member of the family Reoviridae, is classified into eight groups, $\mathrm{A}-\mathrm{H}$, based on the antigenicity of the inner capsid protein VP6. In humans, infection with group A rotavirus (GAR), B (GBR), $\mathrm{C}$ (GCR) and $\mathrm{H}$ (GHR) have been detected to date. Globally, GAR is the leading cause of AGE in children and infections due to GBR and GHR are detected at low levels [2, 3].

GCR infections have been reported in both sporadic and outbreak cases of gastroenteritis worldwide $[4,5]$. However, its epidemiology and ecology remains unclear. Studies indicating low prevalence of antibodies against GCR in urban and high prevalence in rural populations as well as evidence of cross-species transmission highlight the role of GCR as an emerging zoonotic infection in humans, which should be 
constantly monitored in the future [6, 7]. In India, the role of GCR in AGE cases has not been reported until now, and needs to be explored when mass vaccination against GAR is being implemented. The aim of the present study was to screen the cases of AGE for the occurrence of GCR and to study its circulation pattern in western India.

The National Institute of Virology, Pune (India) is engaged in investigations of gastroenteritis outbreaks occurring mainly in western India. Faecal specimens collected from these outbreaks during the period 2006-2014, which were available in adequate quantities for testing were included in the study (Table 1). A total of 253 retrospective faecal specimens collected from AGE outbreaks in rural [Sholapur, March 2010 ( $n=118)$; Sholapur, August $2011 \quad(n=42)$; Miraj, December $2014(n=33)$ ] and urban [Mumbai, October $2006(n=60)]$ regions of Maharashtra state, western India were included in the study (Table 1). The faecal specimens collected from sporadic AGE cases $(n=147)$ admitted to hospitals in Pune $(n=114)$ and Aurangabad $(n=33)$, cities of Maharashtra state, during 2011-2013 were also included in the study. The median age of gastroenteritis patients was 18 years (range 22 days to 86 years). The male:female ratio of AGE patients was 1.04:1 (male 197, female 189). The specimens were collected within $48 \mathrm{~h}$ of hospitalization. All patients were examined for fever, number of episodes and duration of vomiting and diarrhoea, extent of dehydration and treatment. Severity of the disease was assessed by using a 0 - to 20-point score and based on sum of the points, the disease was described as mild, moderate, severe and very severe using the Ruuska \& Vesikari method [8]. Informed consent was obtained from the parents/ patients prior to collection of specimens. The faecal specimens were tested previously for the presence of different bacterial (enterotoxigenic Escherichia coli, Shigella, Vibrio cholerae, Salmonella, Klebsiella) and viral agents (GAR, GBR, norovirus, adenovirus, astrovirus, Aichivirus, enterovirus) [9; Joshi et al., unpublished observations].

GCR RNA was detected by using the partial VP6 gene-based RT-PCR assay using modified C4 primer (reverse) reported by Gouvea et al. [10], MJR1: 5'AGCCACATAGTTCACATTTCATC-3' (1361-1339) and newly designed forward primer MJF1: 5'ACAATWGAYATGATTAGACCAGC-3' (891-913). Briefly, RNA was extracted from freshly prepared $30 \%$ faecal suspensions using TRIzol LS reagent (Invitrogen, USA) according to the manufacturer's protocol. The SuperScript ${ }^{\circledR}$ III One-Step RT-PCR system with Platinum ${ }^{\circledR}$ Taq DNA Polymerase kit (Invitrogen, USA) was used for both cDNA synthesis and PCR amplification in a single tube. RNA was denatured at $97{ }^{\circ} \mathrm{C}$ for $5 \mathrm{~min}$ and was rapidly chilled on ice for $5 \mathrm{~min}$. The reaction was performed with an initial reverse transcription step at $45^{\circ} \mathrm{C}$ for 30 min followed by 45 cycles of amplification $(30 \mathrm{~s}$ at $94{ }^{\circ} \mathrm{C}, 30$ s at $50{ }^{\circ} \mathrm{C}$ and $1 \mathrm{~min}$ at $68^{\circ} \mathrm{C}$ ) and a final extension of $5 \mathrm{~min}$ at $68^{\circ} \mathrm{C}$ in a thermal cycler. All the PCR products were electrophoresed in $2 \%$ agarose gel containing ethidium bromide $(0 \cdot 5 \%)$ and visualized under a UV transilluminator. PCR amplicons were excised from the gel for purification (QIAquick, Qiagen, Germany) and cycle sequencing was conducted using a Big Dye Terminator v. 3.1 cycle sequencing kit (Applied Biosystems, USA) and an ABI 3130XL genetic analyzer (Applied Biosystems). Nucleotide sequence identity was determined through BLAST (www.ncbi.nlm.nih.gov/blast) and phylogenetic analysis was performed using MEGA 6 software [11]. The phylogenetic tree was generated with a neighbour-joining algorithm and the Kimura two-parameter distance model. The reliability of the phylogenetic tree was tested by applying the bootstrap test with 1000 bootstrap replications. The nucleotide sequences of the strains examined in the study have been deposited in GenBank under the accession numbers KT900217KT900236 and KX110051-KX110053.

Ethical approval for the study was obtained from the Institutional Human Ethical Committee of the National Institute of Virology, Pune, India.

Of the 253 and 147 faecal samples tested from outbreak and sporadic cases of AGE, $22(8 \cdot 6 \%)$ and 1 $(0.7 \%)$, respectively, showed the presence of GCR RNA. The distribution of GCR positivity was $8.4 \%$ (10/118), $19 \cdot 0 \%(8 / 42), 9 \cdot 0 \%(3 / 33)$ and $1 \cdot 6 \%(1 / 60)$ in Sholapur 2010, Sholapur 2011, Miraj 2014 and Mumbai 2006 outbreaks, respectively. In GCRpositive specimens collected from different outbreaks $(n=22), 21$ were from rural regions, and 18 of these were from outbreaks occurring during March and August. Clinical severity score of the patients with GCR infection $(n=23)$ indicated severe disease in the majority $(70 \%)$ and moderate disease in the minority $(30 \%)$ of the patients (Table 2). The age distribution analysis indicated occurrence of GCR infections in patients between 9 months and 86 years with $52 \cdot 1 \%$ of the cases in children $(<10$ years). The male:female ratio in GCR-positive patients was $2 \cdot 3: 1$ (male 16, female 7). 
Table 1. Details of patients in outbreaks of acute gastroenteritis occurring in western India during 2006-2014

\begin{tabular}{|c|c|c|c|c|c|}
\hline Outbreak reported & Region & $\begin{array}{l}\text { No. of samples } \\
\text { available for testing/ } \\
\text { no. collected }\end{array}$ & Age group & $\begin{array}{l}\text { Male:female } \\
\text { ratio }\end{array}$ & $\begin{array}{l}\text { GCR RT-PCR } \\
\text { positive/no. } \\
\text { tested }\end{array}$ \\
\hline Mumbai outbreak (October 2006) & Urban & $60 / 211$ & 4 months to 60 years & $\begin{array}{l}1 \cdot 5: 1 \\
(\mathrm{M} \mathrm{36}, \mathrm{F} 24)\end{array}$ & $1 / 60$ \\
\hline Sholapur I (March 2010), & Rural & $118 / 145$ & 6 months to 86 years & $\begin{array}{l}0 \cdot 71: 1 \\
(\mathrm{M} \mathrm{49,} \text { F 69) }\end{array}$ & $10 / 118$ \\
\hline Sholapur II (August 2011) & Rural & $42 / 54$ & 9 months to 50 years & $\begin{array}{l}1: 1 \\
(\mathrm{M} \mathrm{21}, \mathrm{F} 21)\end{array}$ & $8 / 42$ \\
\hline Miraj outbreak (December 2014) & Rural & $33 / 33$ & 9 months to 70 years & $\begin{array}{l}1 \cdot 2: 1 \\
(\mathrm{M} 18, \mathrm{~F} 15)\end{array}$ & $3 / 33$ \\
\hline
\end{tabular}

M, Male (n); F, female (n); GCR, group C rotavirus.

Table 2. Group C rotaviruses detected as sole and mixed infections with other viral and bacterial agents in hospitalized diarrhoeic cases in western India during 2006-2014

\begin{tabular}{|c|c|c|c|c|c|c|}
\hline \multirow[b]{2}{*}{$\begin{array}{l}\text { Strain } \\
\text { no. }\end{array}$} & \multirow[b]{2}{*}{$\begin{array}{l}\text { Age, } \\
\text { years }\end{array}$} & \multirow[b]{2}{*}{ Sex } & \multicolumn{3}{|c|}{ Group $\mathrm{C}$ rotavirus positive } & \multirow[b]{2}{*}{$\begin{array}{l}\text { Severity of the infection using the } \\
\text { Ruuska \& Vesikari scoring scale }\end{array}$} \\
\hline & & & $\begin{array}{l}\text { Sole group } \\
\mathrm{C} \text { rotavirus }\end{array}$ & $\begin{array}{l}\text { Mixed infection with } \\
\text { other viral agents }\end{array}$ & $\begin{array}{l}\text { Mixed infection with } \\
\text { Bacterial agents }\end{array}$ & \\
\hline \multicolumn{7}{|c|}{ Sholapur 2010 (outbreak) } \\
\hline 1 & 5 & $\mathrm{M}$ & Pos. & & & Severe \\
\hline 2 & $2 \cdot 5$ & M & Pos. & & & Severe \\
\hline 3 & 1 & M & Pos. & & & Severe \\
\hline 4 & 55 & $\mathrm{~F}$ & & Enterovirus & & Moderate \\
\hline 5 & 3 & M & Pos. & & & Severe \\
\hline 6 & 86 & M & & Group B rotavirus & & Severe \\
\hline 7 & 35 & M & Pos. & & & Moderate \\
\hline 8 & 6 & M & Pos. & & & Severe \\
\hline 9 & 25 & M & Pos. & & & Severe \\
\hline 10 & 33 & $\mathrm{M}$ & Pos. & & & Moderate \\
\hline \multicolumn{7}{|c|}{ Sholapur 2011 (outbreak) } \\
\hline 11 & 7 & $\mathrm{~F}$ & Pos. & & & Moderate \\
\hline 12 & 50 & M & & & Vibrio cholerae & Severe \\
\hline 13 & 8 & $\mathrm{~F}$ & Pos. & & & Severe \\
\hline 14 & 2 & $\mathrm{~F}$ & & $\begin{array}{l}\text { Aichivirus, } \\
\text { enterovirus }\end{array}$ & & Severe \\
\hline 15 & 9 months & M & Pos. & & & Severe \\
\hline 16 & 1 & M & Pos. & & & Severe \\
\hline 17 & 5 & M & Pos. & & & Severe \\
\hline 18 & 27 & $\mathrm{~F}$ & Pos. & & & Moderate \\
\hline \multicolumn{7}{|c|}{ Miraj 2014 (outbreak) } \\
\hline 19 & 6 & $\mathrm{~F}$ & & & Vibrio cholerae & Moderate \\
\hline 20 & 28 & $\mathrm{~F}$ & & $\begin{array}{l}\text { Group B rotavirus, } \\
\text { norovirus }\end{array}$ & $\begin{array}{l}\text { Enterotoxigenic } \\
\text { Escherichia coli }\end{array}$ & Severe \\
\hline 21 & 35 & $\mathrm{M}$ & Pos. & & & Moderate \\
\hline \multicolumn{7}{|c|}{ Mumbai 2006 (outbreak) } \\
\hline 22 & 45 & $\mathrm{M}$ & Pos. & & & Severe \\
\hline \multicolumn{7}{|c|}{ Pune 2013 (sporadic) } \\
\hline 23 & 61 & $\mathrm{M}$ & Pos. & & & Severe \\
\hline
\end{tabular}

M, Male; F, female; Pos., positive. 


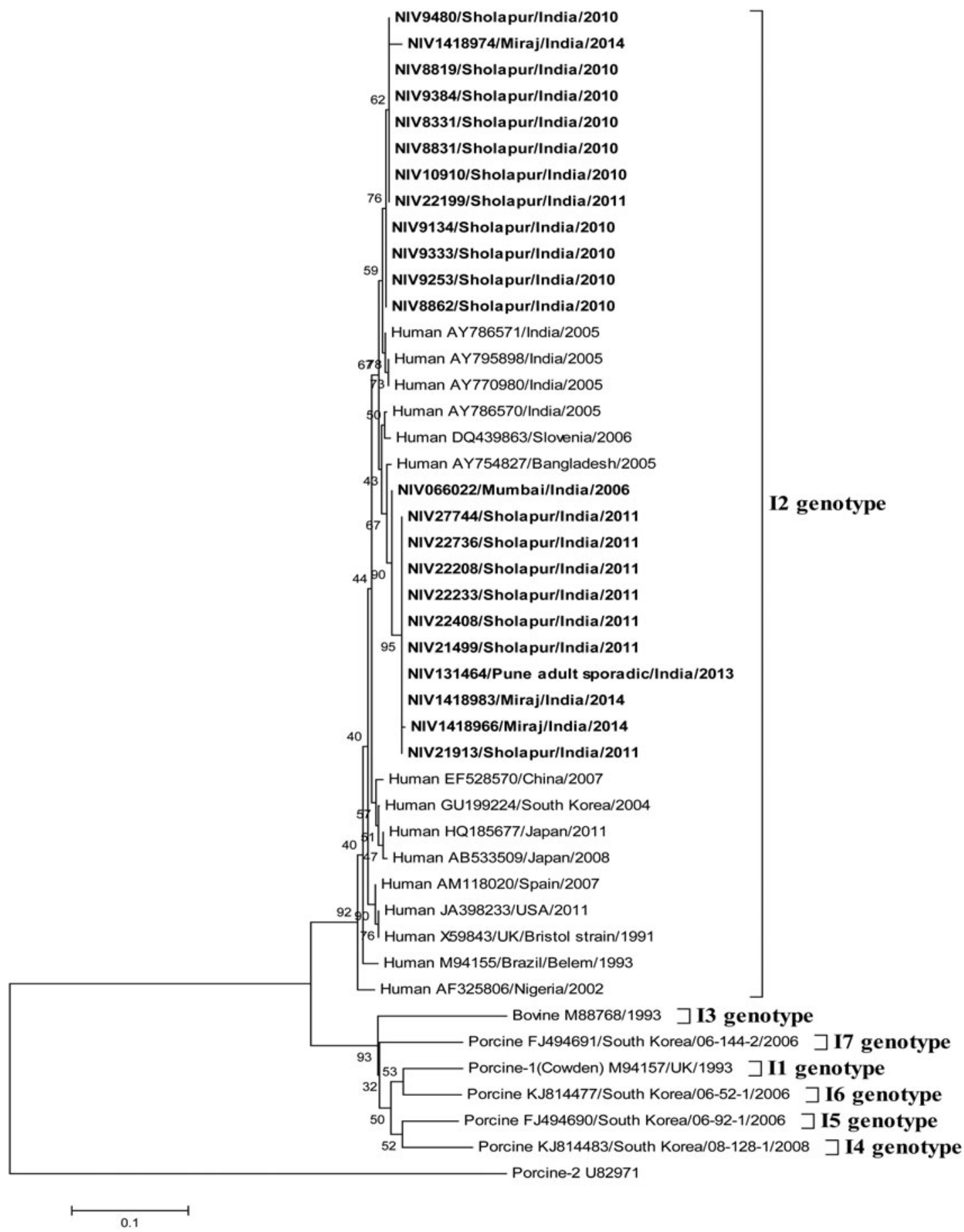

Fig. 1. Phylogenetic tree constructed based on the partial nucleotide sequences of the VP6 gene (372 bp) of group C rotavirus strains. The strains of the present study are indicted by bold font. The reference strains are indicated by accession numbers followed by the country name and year. Scale indicates genetic distances.

Of the GCR-positive clinical specimens $(n=23), 17$ $(73.9 \%)$ were solely GCR positive while the remaining six showed mixed infection with other viral and/or bacterial agents (Table 2). GCR-associated single bacterial or viral mixed infections were detected with Vibrio cholerae $(n=2)$, GBR $(n=1)$ and enterovirus $(n=1)$. Mixed infections with three or four different agents were detected in one specimen each (Table 2).

Phylogenetic analysis of nucleotide sequences classified all GCR strains of the present study in to genotype $I_{2}$ of the VP6 gene (Fig. 1). The study strains isolated from the outbreaks of rural regions (Sholapur 
2010, Sholapur 2011, Miraj 2014) were closer to Indian strain (AY786571) and strains isolated from sporadic (Pune) and outbreak (Mumbai 2006) cases, one each from urban regions and a few outbreak cases from rural regions (Sholapur 2011, Miraj 2014), were closer to Bangladesh strain (AY754827) (Fig. 1). Nucleotide sequence identity in the 23 study strains was between $96.4 \%$ and $100 \%$. The GCR sequences of $\mathrm{I}_{2}$ genotype randomly selected from different countries of the world, including the study strains, showed $95 \cdot 1-100 \%$ nucleotide identity. The study strains showed nucleotide sequence identity in the range of $82 \cdot 1-83 \cdot 0 \%$ with porcine strains $\left(\mathrm{I}_{1}\right.$ and $\mathrm{I}_{4}-\mathrm{I}_{7}$ genotypes) and $79 \cdot 4 \%$ with a bovine strain ( $\mathrm{I}_{3}$ genotype).

The present study suggests the presence of GCR strains of $\mathrm{I}_{2}$ genotype in $8 \cdot 6 \%$ and $0.7 \%$ of outbreak and sporadic gastroenteritis patients, respectively. Molecular epidemiological studies available from different parts of the world indicate that GCR detection rates range between $0 \cdot 3$ and $23 \cdot 7 \%[4,7,12]$. In the absence of molecular epidemiological data from India, atypical rotaviruses serologically related to GCR were detected by electrophoretic migration patterns of double-stranded RNA in $0.43 \%$ of children aged $<3$ years with gastroenteritis in South India [13]. The circulation of GCR in the southern Indian population has also been shown previously by a $25 \cdot 3 \%$ seroprevalence rate [14].

Among the epidemiological features, GCR-infected male patients' outnumbered female patients $(2 \cdot 3: 1)$ and infections were observed in patients of all age groups. Clinical specimens analysed from outbreaks reported from rural regions showed higher GCR positivity $(10.9 \%)$ compared to outbreaks in urban regions $(1.6 \%)$ and were in concordance with an earlier study indicating increased prevalence of GCR in rural regions due to the close proximity of people with animals [7]. The GCR strains circulating among diarrhoeic and non-diarrhoeic porcine and bovine animals in the study region should be studied in future in order to establish the zoonotic origin.

The study has limitations on account of the analysis being restricted to smaller numbers of faecal specimens available from sporadic (urban) and outbreak (urban and rural) cases of gastroenteritis in Maharashtra, western India. Moreover, the faecal specimens of sporadic cases collected from the rural areas and during the same period were not available for GCR screening and hence the exact role of GCR remains unknown for the region where circulation of
GCR in outbreak cases has been observed. Apart from this, the primers used for the detection of GCR were specific for human and bovine GCR strains and therefore the possibility of circulation of porcine GCR strains in the study population is unexplored and warrants further study. The carriage of porcine GCR strains in diarrhoeic and non-diarrhoeic children has been reported earlier [7].

This study highlights the occurrence of GCR in outbreak cases of gastroenteritis for the first time in India. Even though the majority of GCR-positive cases were observed in rural regions, a larger prospective surveillance study is essential to reveal the exact role of GCR as well as the period of its peak activity in gastroenteritis cases in rural and urban regions of India.

\section{ACKNOWLEDGEMENTS}

We are grateful to Dr D. T. Mourya, Director, National Institute of Virology for his constant support during the study. We also acknowledge the cooperation extended by Dr S. D. Chitambar, Dr M. S. Chaddha and Dr K. S. Lole. Thanks are due to Mr Sanjay Tikute and Mr Prabhakar Jadhav for collection of specimens, Mr Atul Walimbe for statistical and phylogenetic analysis and $\mathrm{Mr}$ Manohar Shinde for technical assistance. The funds for the project were provided by the National Institute of Virology, Indian Council of Medical Research, Ministry of Health and Family Welfare, Government of India.

\section{DECLARATION OF INTEREST}

None.

\section{REFERENCES}

1. Fischer Walker CL, Black RE. Diarrhoea morbidity and mortality in older children, adolescents, and adults. Epidemiology and Infection 2010; 138: 1215-1226.

2. Lahon A, et al. Group B rotavirus infection in patients with acute gastroenteritis from India: 1994-1995 and 2004-2010. Epidemiology and Infection 2012; 141: 969-975.

3. Matthijnssens J, et al. VP6-sequence-based cutoff values as a criterion for rotavirus species demarcation. Archives of Virology 2012; 157: 1177-1182.

4. Luchs A, et al. Monitoring of group C rotavirus in children with acute gastroenteritis in Brazil: An emergent epidemiological issue after rotavirus vaccine? Journal of Medical Virology 2011; 83: 1631-1636.

5. Kumazaki M, Usuku S. Epidemiological and genetic analysis of human group $\mathrm{C}$ rotaviruses isolated from outbreaks of acute gastroenteritis in Yokohama Japan, 
between 2006 and 2012. Archives of Virology 2014; 159: 761-771.

6. Gomara MI, et al. Seroepidemiology of group C rotavirus infection in England and Wales. European Journal of Epidemiology 2004; 19: 589-595.

7. Gabbay YB, et al. Evidence for zoonotic transmission of group $\mathrm{C}$ rotaviruses among children in Belém, Brazil. Journal of Medical Virology 2008; 80: 1666-1674.

8. Ruuska T, Vesikari T. Rotavirus disease in Finnish children: use of numerical scores for clinical severity of diarrhoeal episodes. Scandinavian Journal of Infectious Diseases 1990; 22: 259-267.

9. Chitambar SD, et al. Diversity in the enteric viruses detected in outbreaks of gastroenteritis from Mumbai, western India. International journal of Environmental Research and Public Health 2012; 9: 895-915.
10. Gouvea $\mathbf{V}$, et al. Detection of group B and C rotaviruses by polymerase chain reaction. Journal of Clinical Microbiology 1991; 29: 519-523.

11. Tamura K, et al. MEGA6: molecular evolutionary genetics analysis version 6.0. Molecular Biology and Evolution 2013; 30: 2725-2729.

12. Phan TG, et al. Virus diversity and an outbreak of group $\mathrm{C}$ rotavirus among infants and children with AGE in Maizuru city, Japan during 2002-2003. Journal of Medical Virology 2004; 74: 173-179.

13. Brown DWG, et al. Rotavirus epidemiology in Vellore, south India: group, subgroup, serotype and electrophoretype. Journal of Clinical Microbiology 1988; 26: 2410-2414.

14. Mukhopadhya I, et al. Anti-VP6 IgG antibodies against group $\mathrm{A}$ and group $\mathrm{C}$ rotaviruses in south India. Epidemiology and Infection 2010; 138: 442-447. 